\title{
Pré-condicionamento in vitro de plantas de cana-de-açúcar (Saccharum spp.) para tolerância ao estresse salino ${ }^{1}$
}

\author{
Gemima M. de Melo², Marta R. Barbosa ${ }^{3}$, André L. de F. Dias, \\ Lilia Willadino ${ }^{5}$ \& Terezinha R. Camara ${ }^{6}$ \\ ${ }^{1}$ Trabalho selecionado do II INOVAGRI International Meeting, realizado de 13 a 16 de abril de 2014, Fortaleza - CE, Brasil \\ ${ }^{2}$ UFRPE. Recife, PE. E-mail: gemimamelo@hotmail.com (Autor correspondente) \\ ${ }^{3}$ UFRPE. Recife, PE. E-mail: martaribeiro21@hotmail.com \\ ${ }^{4}$ CETENE. Recife, PE. E-mail: andre.dias@cetene.gov.br \\ ${ }^{5}$ UFRPE. Recife, PE. E-mail: willadino.lilia@gmail.com \\ ${ }^{6}$ UFRPE. Recife, PE. E-mail: teca.camara@gmail.com
}

\section{Palavras-chave:}

RB98710

priming in vitro

salinidade

cloreto de sódio

\begin{abstract}
R E S U M O
Avaliou-se a capacidade de adaptação à salinidade de mudas de cana-de-açúcar da variedade RB98710 após précondicionamento (priming) in vitro com cloreto de sódio $(\mathrm{NaCl})$. O experimento foi conduzido no período de maio a outubro de 2013. Plantas foram micropropagadas em biorreatores de imersão temporária, com tratamentos de priming caracterizados pela adição de $25 \mathrm{mM}$ de NaCl, durante 0,12 , 24 e 36 horas. Concluídos os períodos de priming, as plantas foram cultivadas em meio de enraizamento sem $\mathrm{NaCl}$, aclimatizadas e submetidas a tratamento salino gradativo: $\mathrm{S} 0=\operatorname{sem~NaCl} ; \mathrm{S} 1=$ regas com $20 \rightarrow 40 \rightarrow 60 \mathrm{mM}$ de $\mathrm{NaCl}$ acrescido à solução nutritiva, durante 30 dias. Procedeu-se à supressão do $\mathrm{NaCl}$ e avaliaram-se as plantas 15 dias depois. As variáveis foram: matéria seca da parte aérea (MSPA) e radicular (MSR), número de perfilhos, estimativa de clorofila (Chl), conteúdo hídrico relativo e dano de membrana. As plantas pré-condicionadas não reduziram a MSPA quando submetidas ao $\mathrm{NaCl}$. $\mathrm{O}$ efeito do estresse salino sobre a MSR foi anulado nas plantas submetidas ao priming por $24 \mathrm{~h}$. O priming favoreceu o perfilhamento das plantas dos tratamentos por 24 ou $36 \mathrm{~h}$. A recuperação após o estresse, avaliado 15 dias após a supressão do $\mathrm{NaCl}$, não diferiu entre plantas submetidas ou não ao priming. De acordo com os resultados, o priming utilizado na variedade RB98710, pode favorecer a tolerância à salinidade.
\end{abstract}

Key words: RB98710 priming in vitro salinity sodium chloride

\section{Preconditioning in vitro of sugarcane (Saccharum spp.) seedlings to salt stress tolerance}

\begin{abstract}
A B S T R A C T
The capacity of adaptation to the salinity of seedlings of sugarcane variety RB98710 after priming in vitro with sodium chloride $(\mathrm{NaCl})$ was evaluated. The experiment took place in the period May to October 2013. Plants were micropropagated in temporary immersion bioreactor with priming treatments characterized by the addition of 25 $\mathrm{mM} \mathrm{NaCl}$, for $0,12,24$ and 36 hours. Over periods of priming, the plants were grown in rooting medium without $\mathrm{NaCl}$, acclimatized and underwent gradual salt stress : $\mathrm{S} 0=\mathrm{no} \mathrm{NaCl}$; waterings with $\mathrm{S} 1=20 \rightarrow 40 \rightarrow 60 \mathrm{mM} \mathrm{NaCl}$ added to the nutrient solution for 30 days . Proceeded to the suppression of $\mathrm{NaCl}$ and plants were evaluated after 15 days for shoot (SDM) and root dry matter (RDM), tillers number, chlorophyll estimation (Chl), relative water content and membrane damage were evaluated. The preconditioned plants did not reduce the SDM when submitted to salt stress. The effect of salt stress on the RDM was null in the plants of the priming for $24 \mathrm{~h}$. Preconditioning favored the tillering of the plants of the treatments 24 or $36 \mathrm{~h}$. The recovery after the stress, assessed 15 days after the removal of $\mathrm{NaCl}$ did not differ between whether or not subject to priming plants. According to the results the priming used in the RB98710 variety may favor tolerance to salinity.
\end{abstract}

\section{INTRODUÇÃo}

O aumento das áreas degradadas pelo excesso de sais no solo é constante. Estima-se que o avanço da salinidade possa levar à perda de $30 \%$ das terras agricultáveis dentro dos próximos 25 anos e que até o ano 2050 esse prejuízo chegue a 50\% (Ghosh et al., 2011).

O estresse salino é um dos principais fatores que reduz a produtividade das glicófitas e compromete os principais processos metabólicos dos vegetais (Munns \& Tester, 2008; Willadino \& Camara, 2010). O excesso de cloreto de sódio $(\mathrm{NaCl})$ provoca toxidade, desequilíbrio osmótico e iônico em muitas espécies e, como consequência desses efeitos primários pode ocorrer um estresse secundário de caráter oxidativo (Munns \& Tester, 2008; Pandolfi et al., 2012).

A cana-de-açúcar (Saccharum spp.) é uma glicófita, com moderada sensibilidade ao estresse salino. No Nordeste, a Zona da Mata é a região que apresenta as melhores condições 
climáticas para o desenvolvimento da agricultura canavieira, porém essa atividade vem se expandindo para regiões semiáridas (Oliveira \& Braga, 2011) e o êxito dessa expansão depende, em parte, do plantio de variedades que tolerem as condições adversas do Semiárido e sejam capazes de manter uma boa produtividade.

A aplicação de métodos de pré-condicionamento (priming) é uma estratégia que pode promover a rustificação das plantas, proporcionando maior tolerância aos fatores de estresse abiótico. O priming consiste em uma exposição prévia a um fator de estresse biótico ou abiótico com o objetivo de deixar a planta mais tolerante quando exposta a um novo ciclo de estresse (Patade et al., 2009). Essa técnica é bastante difundida em sementes (seed priming) por promover atividades prémetabólicas, proporcionado aumento da velocidade da taxa germinativa e maior uniformidade das plântulas cultivadas sob condições adversas (Nascimento, 2004; Atreya et al., 2009; Bakht et al., 2011). A aplicação de tratamentos de priming com $\mathrm{NaCl}$ em rebolos de cana-de-açúcar reduziu os efeitos inibitórios da salinidade na germinação e no crescimento das plântulas, em termos de produção de matéria fresca e seca (Patade et al., 2009).

Atualmente um sistema eficiente para produção de mudas de cana-de-açúcar de qualidade e em larga escala é a micropropagação, já estabelecida como rotina em muitos países. No Brasil, alguns laboratórios ou biofábricas produzem mudas micropropagadas de diversas espécies incluindo variedades elite de cana-de-açúcar. A eficiência deste sistema foi potencializada com a utilização de biorreatores de imersão temporária (BIT), os quais aumentam significativamente as taxas de crescimento e multiplicação e melhoram a qualidade das plantas produzidas (Gerald \& Lee, 2011).

O presente estudo objetivou associar as técnicas de pré-condicionamento e de micropropagação em mudas de cana-de-açúcar da variedade RB98710, durante a última etapa de multiplicação in vitro visando avaliar o efeito do précondicionamento com $\mathrm{NaCl}$ sobre a tolerância à salinidade das mudas cultivadas sob estresse salino após a aclimatização.

\section{MATERIAL E Métodos}

O experimento foi desenvolvido na Biofábrica Governador Miguel Arraes, localizada no Centro de Tecnologias Estratégicas do Nordeste (CETENE), no período de maio a outubro de 2013.

Plantas de cana-de-açúcar da variedade RB98710 foram micropropagadas em biorreatores de imersão temporária (BIT), contendo um litro de meio de cultivo, em um ciclo de imersão constituído por oito imersões diárias de dois minutos cada. O meio de cultivo na fase de multiplicação foi composto pelos sais e vitaminas MS (Murashige \& Skoog, 1962), suplementado com $30 \mathrm{~g} \mathrm{~L}^{-1}$ de sacarose; $0,1 \mathrm{~g} \mathrm{~L}^{-1}$ de inositol; $0,2 \mathrm{mg} \mathrm{L}^{-1}$ de 6-benzilaminopurina (BAP); 0,1 $\mathrm{mg} \mathrm{L}^{-1}$ de cinetina (KIN); 0,05 $\mathrm{g} \mathrm{L}^{-1}$ de ácido cítrico e $0,05 \mathrm{~g} \mathrm{~L}^{-1}$ de ácido ascórbico.

Durante a fase de multiplicação as plantas receberam tratamentos de pré-condicionamento (priming), caracterizados pela adição de $25 \mathrm{mM}$ de $\mathrm{NaCl}$ ao meio de cultivo, durante três diferentes períodos de imersão: 12, 24 e $36 \mathrm{~h}$ (priming 1, priming 2 e priming 3 , respectivamente), além do tratamento controle (sem priming).

Após a fase de multiplicação foi suprimido o $\mathrm{NaCl}$ e as plantas passaram para a etapa de enraizamento em meio com composição similar ao meio de multiplicação, acrescido de 1 $\mathrm{mg} \mathrm{L}^{-1}$ de ácido naftalenoacético (ANA), porém sem adição de BAP e da KIN.

Durante todo o período experimental in vitro as plantas foram mantidas em sala de crescimento com temperatura de $25 \pm 2{ }^{\circ} \mathrm{C}$, sob fotoperíodo de $16 \mathrm{~h}$ e intensidade luminosa de $50 \mu \mathrm{mol} \mathrm{m} \mathrm{s}^{-2}$.

As plantas foram aclimatizadas em bandejas de polipropileno com 98 células, contendo o substrato comercial Carolina Soil ${ }^{\circ}$. As plantas permaneceram em estufa durante 30 dias quando, então, foram transferidas para sacos de polietileno contendo areia lavada e permaneceram nesta condição durante 10 dias. Durante o cultivo em areia lavada as plantas foram fertigadas diariamente com uma solução nutritiva composta por 0,7428 $\mathrm{g} \mathrm{L}^{-1}$ de Kristalon e $0,84 \mathrm{~g} \mathrm{~L}^{-1}$ de Calcinit.

No estabelecimento dos tratamentos de estresse ex vitro as plantas receberam a solução de rega com metade da força iônica e acrescida de $\mathrm{NaCl}$. O aumento na concentração salina na solução de rega ocorreu com um incremento de $20 \mathrm{mM}$ de $\mathrm{NaCl}$ a cada 10 dias, de forma a criar um estresse salino gradativo, durante 30 dias. Foram adotados dois tratamentos: $\mathrm{S} 0=$ sem $\mathrm{NaCl}$, com condutividade elétrica de $1,20 \mathrm{dS} \mathrm{m}^{-1}$; $\mathrm{S} 1=20 \rightarrow 40 \rightarrow 60 \mathrm{mM}$ de $\mathrm{NaCl}$, com condutividade elétrica de 3,49; 4,50 e $8,00 \mathrm{dS} \mathrm{m}^{-1}$, respectivamente. Após 30 dias de tratamento salino foi suprimido o $\mathrm{NaCl}$ do $\mathrm{S} 1$ e as plantas foram mantidas por 15 dias com solução não salina, para avaliar a recuperação ao estresse.

De cada tratamento foram coletadas cinco repetições aos 30 dias de estresse e outras cinco após 45 dias para avaliações do efeito do $\mathrm{NaCl}$ e da recuperação ao estresse salino.

As variáveis analisadas foram: matéria seca da parte aérea (MSPA) e da raiz (MSR), número de perfilhos (NP), estimativa do conteúdo de clorofila (índice SPAD - Chl), conteúdo hídrico relativo (CHR) e percentual de dano de membrana (\%D).

O número de perfihos foi contado ao término do experimento. As amostras de parte aérea e raiz foram secas em estufa de aeração à temperatura de $70^{\circ} \mathrm{C}$ até peso constante para determinação da matéria seca.

A estimativa de clorofila foi obtida com clorofilômetro (SPAD-502 Plus, Spctrum Technologies), com leituras em três pontos da primeira folha totalmente expandida, evitando a nervura central.

O conteúdo hídrico relativo (CHR) foi obtido a partir de cinco discos foliares com 5,0 mm de diâmetro, sem a nervura central. Os discos foram pesados para a determinação da massa fresca (MF) e acondicionados em placas de Petri com água destilada, durante $24 \mathrm{~h}$. Posteriormente, foi realizada nova pesagem para obtenção da massa túrgida (MT) dos discos, que foram, então, mantidos a $40^{\circ} \mathrm{C}$ por $24 \mathrm{~h}$, para obtenção da massa seca (MS). O CHR foi calculado segundo metodologia de Barrs \& Weatherley (1962), aplicando-se a Eq. 1: 


$$
\mathrm{CHR}=\frac{(\mathrm{MF}-\mathrm{MS})}{(\mathrm{MT}-\mathrm{MS})} \times 100 \%
$$

O percentual de dano de membrana (\%D) foi estimado a partir do extravasamento de eletrólitos (adaptado de Azevedo et al., 2008). Discos foliares com 5,0 mm de diâmetro permaneceram, durante $24 \mathrm{~h}$, imersos em $20 \mathrm{~mL}$ de água destilada em tubos de ensaio. Em seguida foi medida a condutividade elétrica livre (L1) e os tubos de ensaio foram colocados em banho-maria por uma hora a $100{ }^{\circ} \mathrm{C}$. Após o banho, ao atingirem a temperatura ambiente foi realizada a segunda leitura de condutividade elétrica, a condutividade elétrica total (L2). O \%D foi estimado pela Eq. 2:

$$
\% \mathrm{D}=\frac{\mathrm{L} 1}{\mathrm{~L} 2} \times 100
$$

O experimento foi realizado em um arranjo fatorial $4 \times 2$, constituído de quatro tratamentos de priming in vitro $(0,12$, 24 e $36 \mathrm{~h}$ ) e dois níveis salinos ( $\mathrm{S} 0=\mathrm{sem} \mathrm{NaCl}$ (controle); $\mathrm{S} 1$ $=20 \rightarrow 40 \rightarrow 60 \mathrm{mM}$ de $\mathrm{NaCl}$ ), em delineamento experimental inteiramente casualizado. Foram utilizadas quatro repetições durante a fase in vitro e dez repetições por tratamento na fase de estufa. Os resultados foram submetidos à análise de variância (ANOVA) e as médias foram comparadas pelo teste de Tukey a 0,05 de probabilidade, utilizando o software Assistat 7.7 beta (Assis \& Silva, 2013).

\section{Resultados e Discussão}

As plantas pré-condicionadas com o $\mathrm{NaCl}$ não apresentaram redução da massa seca da parte aérea (MSPA) quando submetidas ao estresse salino, ao contrário daquelas que não foram submetidas ao priming in vitro (Figura 1A). As plantas provenientes do priming in vitro por $24 \mathrm{~h}$ apresentaram maior massa seca radicular (MSR) sob tratamento salino quando comparadas ao controle. Nas plantas dos demais tratamentos houve redução da MSR sob rega salina (Figura 1B).

A redução da biomassa em plantas submetidas a estresse salino já foi bastante documentada, inclusive para cana-deaçúcar (Ashraf et al., 2010). Estudos recentes realizados com aplicação de pré-tratamento em rebolos de uma gema com $100 \mathrm{mM}$ de $\mathrm{NaCl}$ registram aumento no comprimento e no peso fresco de brotos e raízes de variedades de cana-de-açúcar provenientes de rebolos submetidos a estresse iso-osmótico com 0,7 MPa, induzido com $\mathrm{NaCl}(150 \mathrm{mM})$ ou PEG-8000 $(20 \%, \mathrm{p} / \mathrm{v})$ (Patade et al., 2009). Outras gramíneas também responderam positivamente ao pré-condicionamento, como descrito para a cultivar Azam y de Zea mays, provenientes da germinação de sementes pré-condicionadas em $\mathrm{NaCl}$ a $6 \mathrm{dS} \mathrm{m}^{-1}$. Essas plantas também apresentaram aumento significativo da matéria seca, quando comparadas com aquelas provenientes de sementes não pré-condicionadas (Bakht et al., 2011). De acordo com Levitt (1980), as plantas, em geral, não desenvolvem tolerância ao estresse a menos que sejam

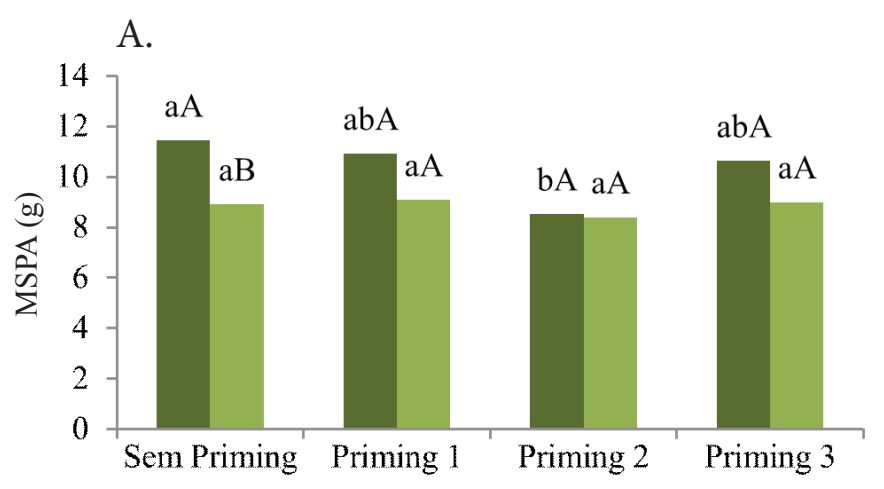

B.

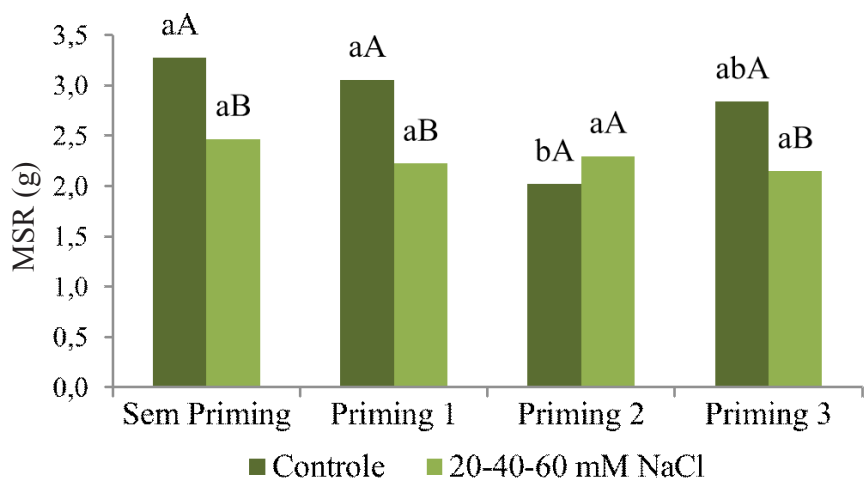

Médias seguidas de mesma letra minúscula entre tratamentos de priming e mesma letra maiúscula entre tratamentos salinos, não diferem entre si pelo teste de Tukey a 0,05 de probabilidade

Figura 1. Massa seca da parte aérea - MSPA (A) e massa seca da raiz - MSR (B) das plantas de cana-de-açúcar da variedade RB98710, provenientes de aplicação de priming com $25 \mathrm{mM}$ de cloreto de sódio $(\mathrm{NaCl})$, durante 0 (sem priming), 12 (priming 1), 24 (priming 2) e 36 (priming 3 ) h, submetidas a tratamentos de estresse salino gradativo em estufa: $\mathrm{S} 0=$ controle sem NaCl; $\mathrm{S} 1=20 \rightarrow 40 \rightarrow 60 \mathrm{mM}$ de $\mathrm{NaCl}$, durante 30 dias

submetidas a condições estressantes. Isto significa que elas precisam passar por um processo de rustificação para tolerar um novo ciclo de estresse (Rivas et al., 2013). A tolerância ao estresse depende não apenas da intensidade e duração da exposição ao agente estressor, mas também do número de eventos estressantes a que a planta foi submetida (Chaves et al., 2009). Experimentos com plântulas de Arabdopsis registram que o priming hiperosmótico estabelece uma memória somática de longo prazo acompanhada por mudanças específicas no epigenoma que compreendem diferenças no status da cromatina, na responsividade transcricional, bem como na fisiologia da planta inteira (Sani et al., 2013).

O pré-condicionamento in vitro por $12 \mathrm{~h}$ de exposição ao $\mathrm{NaCl}$ não foi suficiente para evitar a redução no perfilhamento quando essas plantas foram submetidas ao estresse salino ex vitro. Por outro lado, os tratamentos de priming com duração de 24 e $36 \mathrm{~h}$ preveniram o efeito deletério do $\mathrm{NaCl}$ sobre o perfilhamento das plantas submetidas ao estresse salino ex vitro, de maneira que o número de perfilhos não diferiu entre estressadas e controle (Figura 2A). A cana-de-açúcar apresenta quatro fases de crescimento características da cultura e entre 
A.

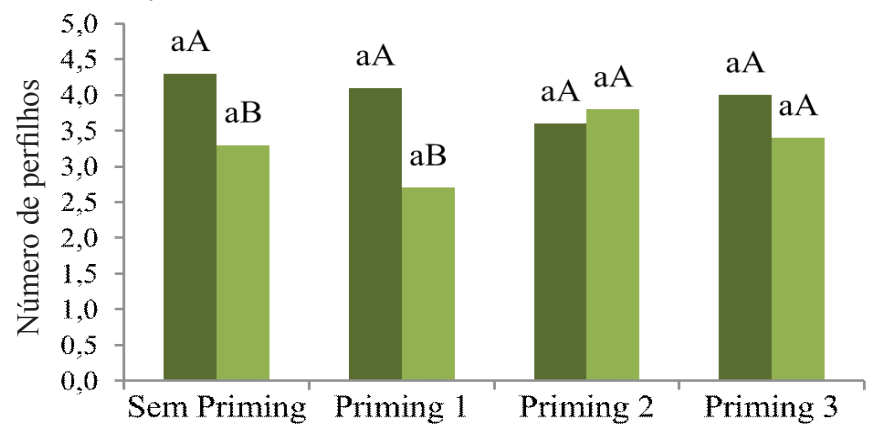

B.

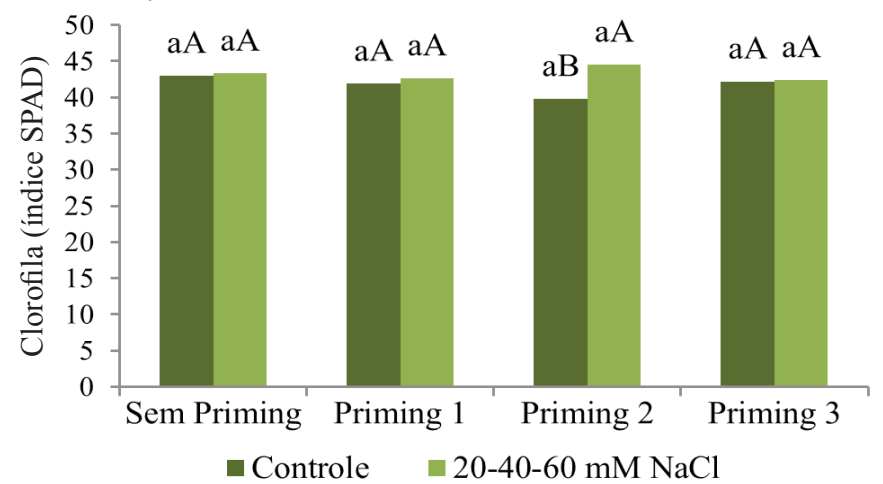

Médias seguidas de mesma letra minúscula entre tratamentos de priming e mesma letra maiúscula entre tratamentos salinos, não diferem entre si pelo teste de Tukey a 0,05 de probabilidade

Figura 2. Número de perfilhos (A) e estimativa de clorofila - Chl (B) pelo índice SPAD das plantas de cana-de-açúcar da variedade RB98710, provenientes de aplicação de priming com $25 \mathrm{mM}$ de cloreto de sódio $(\mathrm{NaCl}$ ), durante 0 (sem priming), 12 (priming 1), 24 (priming 2) e 36 (priming 3) h, submetidas a tratamentos de estresse salino gradativo em estufa: S0 $=$ controle sem NaCl; $\mathrm{S} 1=20 \rightarrow 40 \rightarrow 60 \mathrm{mM}$ de $\mathrm{NaCl}$, durante 30 dias

elas a de perfilhamento começa em geral aos 40 dias após o plantio e pode durar até 120 dias. Esta é uma das fases mais exigentes em água e, juntamente com a fase de crescimento intenso do colmo, constitui a formação propriamente dita da cultura (Ramesh, 2000). O pré-condicionamento pode, portanto, ser uma alternativa importante para assegurar um bom perfilhamento em mudas de cana-de-açúcar sob estresse osmótico nesta fase de crescimento.

$\mathrm{O}$ tratamento de priming in vitro por $24 \mathrm{~h}$ induziu um aumento no teor de clorofila (índice SPAD) de plantas submetidas ao estresse salino (Figura 2B). A salinidade é capaz de reduzir o teor de pigmentos fotossintéticos em plantas sensíveis à salinidade e aumentar em plantas tolerantes ao ambiente salino. O efeito sobre o teor da clorofila depende da concentração do agente estressor, bem como da espécie vegetal (Jamil et al., 2007). Sob estresse hídrico variedades sensíveis de cana-de-açúcar apresentaram redução mais drástica no índice SPAD do que as variedades tolerantes à seca (Silva et al., 2007).

De acordo com alguns autores, o índice SPAD é uma medida sensível e de fácil obtenção que poderia ser utilizada para comparar a tolerância ao estresse (O’Neill et al., 2006). No caso da variedade RB98710 o efeito sobre a clorofila foi visivelmente dependente da duração do priming in vitro, com o tratamento por $24 \mathrm{~h}$ favorecendo uma resposta de tolerância ao estresse salino pós-priming.

As plantas submetidas ao pré-condicionamento in vitro mantiveram o CHR quando expostas ao estresse salino ex vitro (Figura 3A). Entre as plantas estressadas, o menor valor de CHR foi observado nas plantas que não foram pré-condicionadas com $\mathrm{NaCl}$ in vitro. O período experimental coincidiu com a fase de perfilhamento das plantas, um período crítico de demanda hídrica. Silva et al. (2007) sugerem que medidas de relações hídricas em plantas sob estresse osmótico durante esta fase de crescimento podem ser úteis na identificação de tolerância à seca e que a manutenção do CHR é mais frequente em genótipos tolerantes.

Não se observou efeito significativo do priming sobre a percentagem de dano de membrana nas plantas tratadas com estresse salino, entretanto, as plantas provenientes do tratamento in vitro por $36 \mathrm{~h}$ apresentaram menor \%D quando submetidas ao estresse salino ex vitro do que as plantas do controle (Figura 3B). Os danos na membrana ocorrem em consequência da

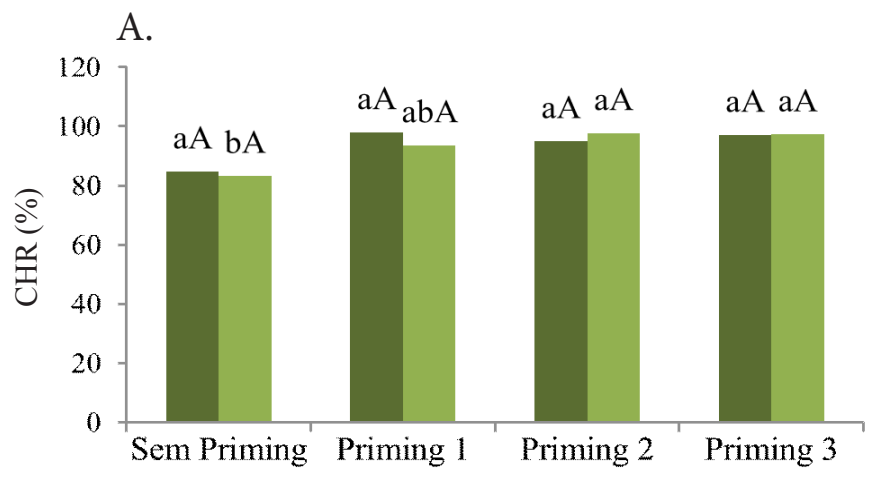

B.

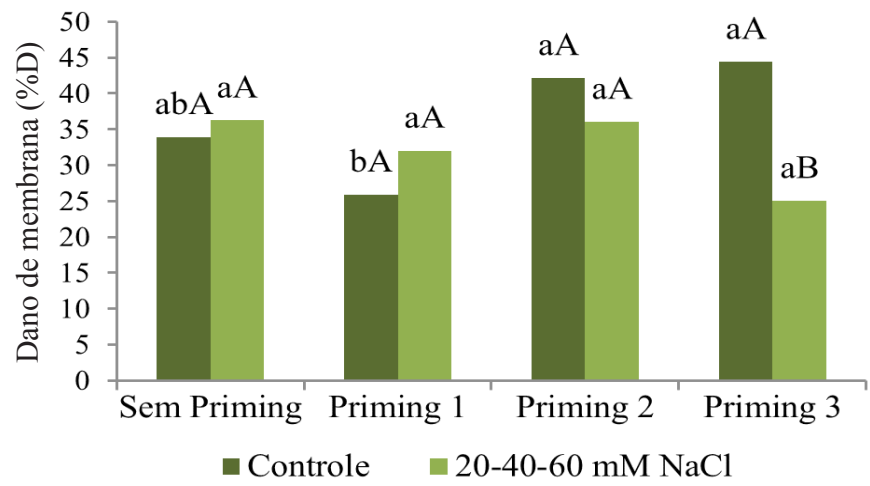

Médias seguidas de mesma letra minúscula entre tratamentos de priming e mesma letra maiúscula entre tratamentos salinos, não diferem entre si pelo teste de Tukey a 0,05 de probabilidade

Figura 3. Conteúdo hídrico relativo - $\mathrm{CHR}(\mathrm{A})$ e dano de membrana (B) das plantas de cana-de-açúcar da variedade RB98710, provenientes de aplicação de priming com $25 \mathrm{mM}$ de cloreto de sódio $(\mathrm{NaCl})$, durante 0 (sem priming), 12 (priming 1), 24 (priming 2) e 36 (priming 3) h, submetidas a estresse salino gradativo em estufa: $\mathrm{S} 0=$ controle sem $\mathrm{NaCl} ; \mathrm{S} 1=$ $20 \rightarrow 40 \rightarrow 60 \mathrm{mM}$ de $\mathrm{NaCl}$, durante 30 dias 
peroxidação de lipídios provocada pelo excesso de Espécies Reativas de Oxigênio (ROS), em situações de estresse oxidativo (Silveira et al., 2005; Harrir \& Mitller, 2009). Entre as plantas do tratamento controle ex vitro a menor $\% \mathrm{D}$ foi registrada nas plantas pré-condicionadas in vitro por $12 \mathrm{~h}$ com $\mathrm{NaCl}$. $\mathrm{O}$ priming parece equipar a planta com meios de prevenir o dano oxidativo mesmo na ausência de fatores de estresse, que normalmente provocam tais respostas (Sani et al., 2013).

Durante os 15 dias de avaliação da recuperação ao estresse, quando o $\mathrm{NaCl}$ foi suprimido, não ocorreram diferenças significativas entre os tratamentos de priming, para as diferentes variáveis avaliadas (Figura 4). Apenas a produção de matéria seca da parte aérea das plantas que passaram pelo estresse salino não se igualou a das plantas do tratamento controle após 15 dias de supressão do $\mathrm{NaCl}$, seguramente devido ao pequeno tempo

A.

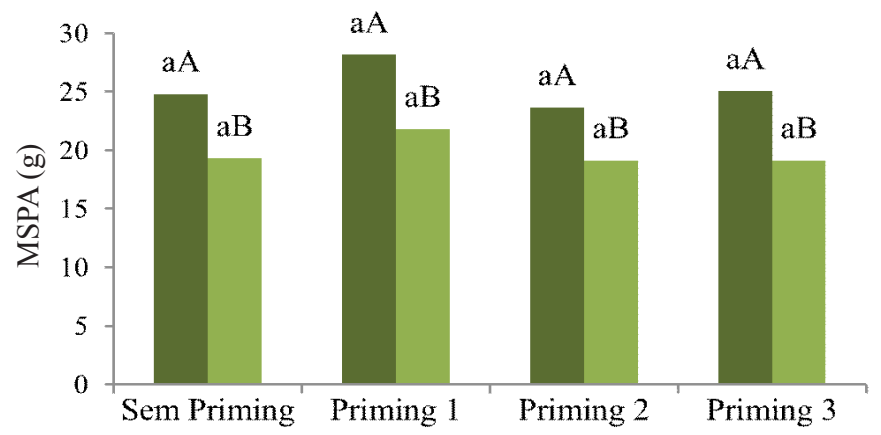

C.

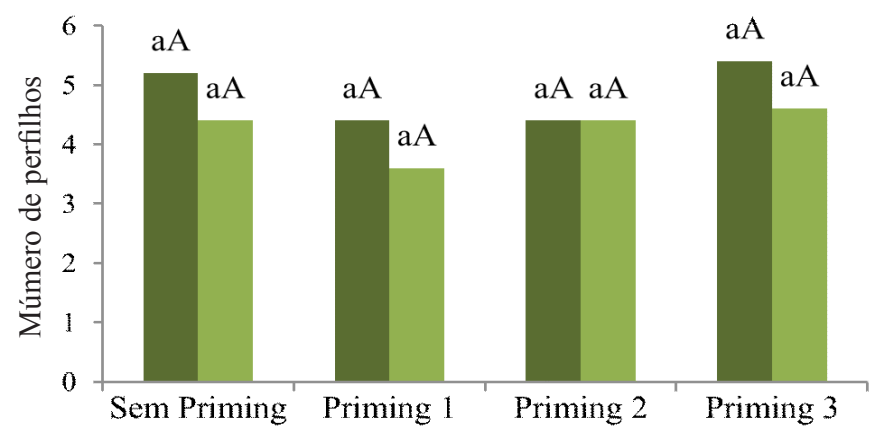

E.

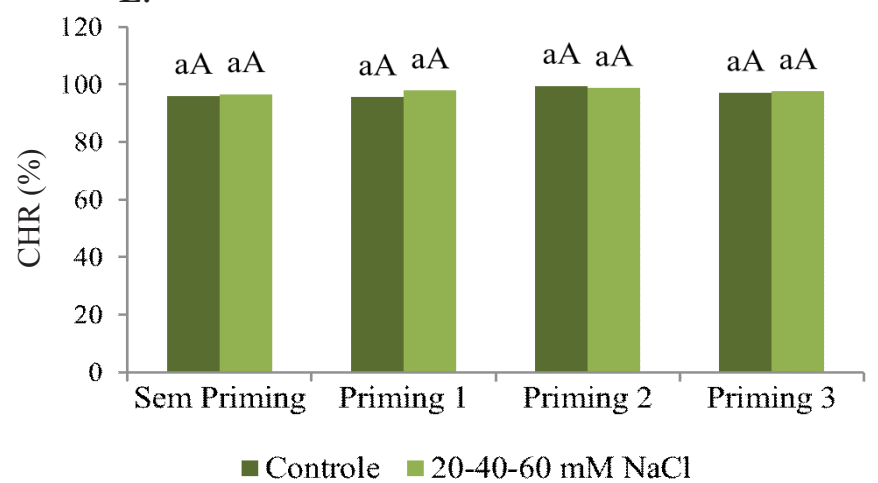

de recuperação das plantas. Esta resposta foi independente dos tratamentos de priming in vitro.

Os resultados obtidos nesse experimento confirmam que as plantas que foram pré-condicionadas com o $\mathrm{NaCl}$ sofreram ajustes no seu metabolismo, o que foi importante para manter a homeostase durante a exposição ao estresse salino. A intensidade e a duração do priming proporcionaram respostas favoráveis, um resultado que corrobora com Lichtenthaler (2004), o qual define o eu-estresse como uma condição de estresse suave e estimulante, capaz de ativar o metabolismo celular e incrementar a atividade fisiológica da planta, comportando-se como fator positivo que impulsiona o crescimento vegetal. Os tratamentos condicionantes invocam a "memória celular" e, portanto, a intensidade e duração de tais tratamentos precisam ser cuidadosamente manipuladas para evitar qualquer impacto

B.

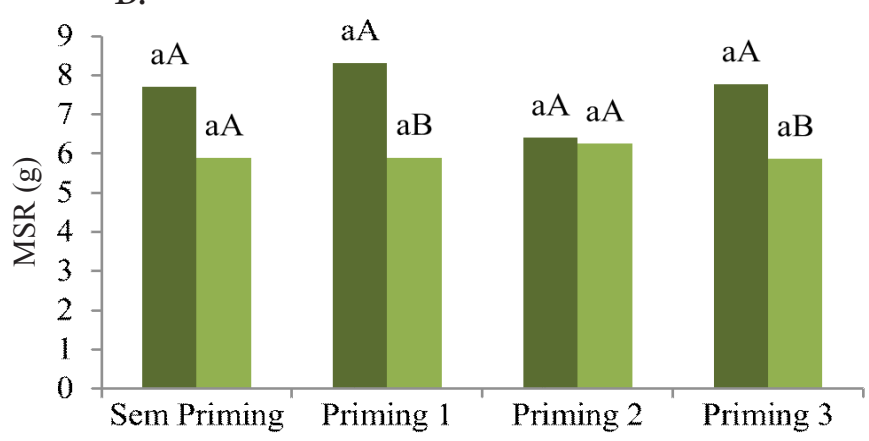

D.

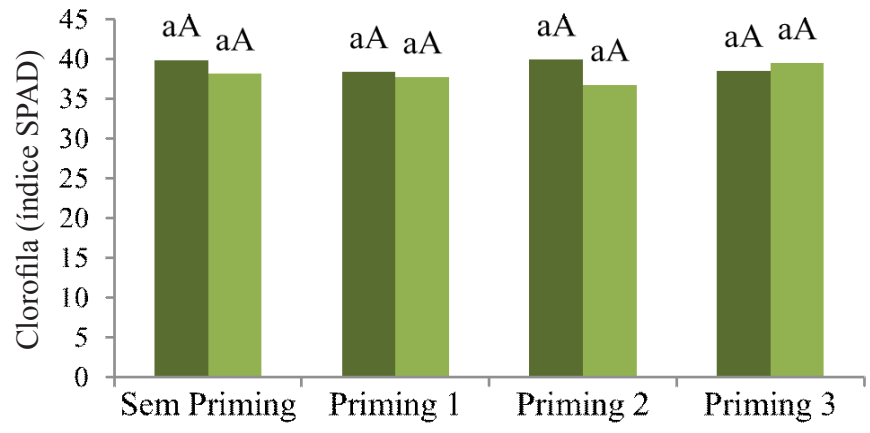
F.

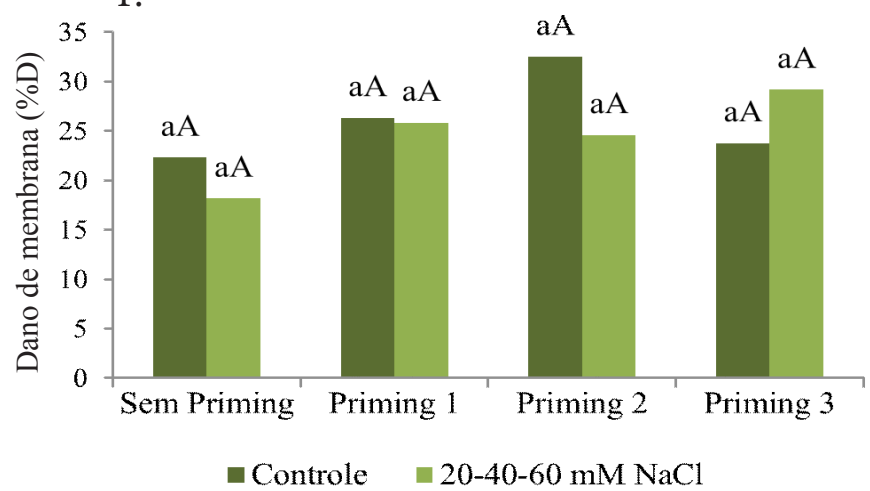

Médias seguidas de mesma letra minúscula entre tratamentos de priming e mesma letra maiúscula entre tratamentos salinos, não diferem entre si pelo teste de Tukey a 0,05 de probabilidade.

Figura 4. Massa seca da parte aérea - MSPA (A); massa seca da raiz - MSR (B); número de perfilhos (C); estimativa de clorofila - Chl, pelo índice SPAD (D); conteúdo hídrico relativo - CHR (E) e dano de membrana (F) das plantas de cana-de-açúcar da variedade RB98710, provenientes de aplicação de priming com 25 mM de cloreto de sódio $(\mathrm{NaCl})$, durante 0 (sem priming), 12 (priming 1), 24 (priming 2) e 36 (priming 3) h, após 15 dias de supressão do $\mathrm{NaCl}$ (recuperação ao estresse) 
negativo sobre a velocidade e adequação do sistema de defesa (Sani et al., 2013). Ainda de acordo com Sani et al., (2013), o priming com $\mathrm{NaCl}$ altera resposta da planta adulta ao estresse salino e hídrico e causa pequenas mas significativas mudanças em histonas. Os autores registraram também que mais de 100 genes apresentaram diferenças persistentes, um dos quais codifica o transportador de Na HKT1 que é induzido mais fortemente nas plantas que receberam o priming do que nas que não receberam, quando expostas ao segundo ciclo de estresse salino.

Nesse contexto, conclui-se que o pré-condicionamento in vitro por $24 \mathrm{~h}$ com $25 \mathrm{mM}$ de $\mathrm{NaCl}$ favoreceu os parâmetros de crescimento nas plantas da variedade RB98710 quando submetidas a 30 dias de estresse salino gradativo até $60 \mathrm{mM}$ de $\mathrm{NaCl}$ e que o efeito do priming expressou-se mesmo após um período de 60 dias até a exposição ao novo ciclo de estresse, que embora induzido pelo mesmo agente estressor, foi imposto a uma concentração e por um tempo de exposição maior do que no tratamento de priming.

\section{Conclusão}

A aplicação do priming com cloreto de sódio, durante a fase de multiplicação da variedade RB98710 pode ser uma prática simples e capaz de favorecer a resistência dessa variedade à salinidade.

\section{Agradecimentos}

Agradecemos ao Conselho Nacional de Desenvolvimento Científico e Tecnológico - CNPq e a FACEPE pelo financiamento do projeto e concessão da bolsa e ao CETENE pela infraestrutura.

\section{Literatura Citada}

Ashraf, M.; Rahmatullah; Ahmad, R.; Bhatti, A. S.; Afzal, M. ; Sarwar, A.; Maqsood, M. A.; Kanwal, S. Amelioration of salt stress in sugarcane (Saccharum officinarum L.) by supplying potassium and silicone in hydroponics. Pedosphere, v.20, p.153-162, 2010.

Assis, E.; Silva, F. A. Z. Assistat 7.7 beta. Campina Grande: UFCG, 2013.

Atreya, A; Vartak, V.; Bhargava, S. Salt priming improve tolerance to dessication stress and to extreme salt stress in Bruguiera cylindrica. International Journal of Integrative Biology, v.6, p.68-73, 2009.

Azevedo, I. G.; Oliveira, J. G.; Silva, M. G. da; Pereira, T.; Corrêa, S. F.; Vargas, H.; Façanha, A. R., P-type H+-ATPases activity, membrane integrity, and apoplastic $\mathrm{pH}$ during papaya fruit ripening. Postharvest Biology and Tchnology, v.48, p.242247, 2008.

Bakht, J.; Shafi, M.; Jamal, Y.; Sher, H. Response of maize (Zea mays L.) to seed priming with $\mathrm{NaCl}$ and salinity stress. Spanish Journal of Agricultural Research, v.9, p.252-261, 2011.
Barrs, H. D.; Weatherley, P. E. A re-examination of the relative turgidity technique for estimating water deficits in leaves. Australian Journal of Biological Science, v.15, p.413-428, 1962.

Chaves; M. M.; Flexas, J.; Pinheiro, C. Photosynthesis under drought and salt stress: Regulation mechanisms from whole plant to cell. Annals of Botany, v.103, p.551-560, 2009.

Gerald, L. T. S.; Lee, L. L. Biofábrica de plantas: Por que biorreator? In: Gerald, L. T. S. Biofábrica de plantas: Produção industrial de plantas in vitro. São Paulo: Antiqua, 2011. Cap.1, p.14-31.

Ghosh, N.; Adak, M. K.; Ghosh, P. D.; Gupta, S.; Sen Gupta, D. N.; Mandal, C. Differential responses of two rice varieties to salt stress. Plant Biotechnology Report, v.5, p.89-103, 2011.

Harrir, Y.; Mittler, R. The ROS Signaling Network of Cells. In: Del Rio, L. A.; Puppo, A. (ed) Reactive oxygen species in plants signaling. Berlin: Springer-Verlag, 2009. p.165-174.

Levitt, J. Responses of plant to environmental stresses. v.1 New York: Academic Press, 1980. 698p.

Lichtenthaler, H. K. El estrés y la medida del estrés en plantas. In: Reigosa, M. J.; Pedrol, N.; Sánchez, A. (ed) La ecofisiología vegetal - Una ciencia de síntesis. Madrid: Thomson, 2004. cap. 2, p.59-111.

Jamil, M.; Rehman, S.; Lec, K. J.; Kim, J. M.; Kim, H. S.; Rha, E. S. Salinity reduced growth PS2 photochemistry and chlorophyll content in radish. Scientia Agrícola, v.64, p.111$118,2007$.

Munns, R.; Tester, M. Mechanisms of salinity tolerance. Annual Review of Plant Biologyis, v.59, p.651-681, 2008.

Murashige, T.; Skoog, F. A revised medium for rapid growth and bioassays with tobacco tissue cultures. Physiologia Plantarum, v.15, p.473-497, 1962.

Nascimento, W. M. Condicionamento osmótico de sementes de hortaliças. Brasília: Empresa Brasileira de Pesquisa Agropecuária, 2004. 12p. Circular Técnica, 33

Oliveira, A. R. de; Braga, M. B. Florescimento e acamamento de cultivares de cana-de-açúcar submetidas a diferentes lâminas de irrigação. Petrolina: Empresa Brasileira de Pesquisa Agropecuária - Embrapa Semiárido, 2011.23p. Boletim de Pesquisa e Desenvolvimento, 87.

O’Neill, P. M.; Shanahan, J. F.; Schepers, J. S.; Use of chlorophyll fluorescence assessments to differentiate corn hybrid response to variable water conditions. Crop Science, v.4, p.681-687, 2006.

Pandolfi, C.; Mancusoa, S.; Shabalab, S. Physiology of acclimation to salinity stress in pea (Pisum sativum). Environmental and Experimental Botany, v.84. p.44-51, 2012.

Patade, V. Y.; Bhargava, S.; Suprasanna, P. Halopriming imparts tolerance to salt and PEG induced drought stress in sugarcane. Agriculture, Ecosystems and Environment, v.134, p.24-28, 2009. 
Ramesh, P. Effect of different levels of drought during the formative phase on growth parameters and its relationship with dry matter accumulation in sugarcane. Journal of Agronomy and Crop Science, v. 185, p.83-89, 2000.

Rivas, R.; Oliveira, M. T.; Santos, M. G. Three cycles of water deficit from seed to young plants of Moringa oleifera woody species improves stress tolerance. Plant Physiology and Biochemistry, v.63, p.200-208, 2013.

Sani, E.; Herzyk, P.; Perrella, G.; Colot, V.; Amtmann, A. Hyperosmotic priming of Arabidopsis seedlings establishes a long-term somatic memory accompanied by specific changes of the epigenome. Genome Biology, v.14, p.2-23, 2013.
Silva, M. de A.; Jifon, J. L.; Silva, J. A. G. da; Sharma, V. Use of physiological parameters as fast tools to screen for drought tolerance in sugarcane. Brazilian Journal of Plant Physiology, v.19, p.193-201, 2007.

Silveira, J. A. G.; Lima, J. P. M. S.; Cavalcanti, F. R.; Maia, J. M.; Viégas, R. A. Salt induced oxidative response in plants: damage or protection? In: Nogueira, R. J. M. C.; Araújo, E. de L.; Willadino, L.; Cavalcante, U. M. T. Estresses ambientais: Danos e benefícios em plantas. Recife: MXM, 2005. p.106-117.

Willadino, L.; Camara, T. R. Tolerância das plantas à salinidade: Aspectos fisiológicos e bioquímicos. Enciclopédia Biosfera, v.6, p.1-23, 2010. 